\title{
Debates em torno das políticas públicas para a modernização da agricultura
}

Fábio Adriano Ortiz ${ }^{1}$

Resumo: Este artigo tem por base trabalho de conclusão de curso que venho desenvolvendo e seu objeto de investigação são as políticas relativas à modernização da agricultura e ao ensino rural implementadas pelo Estado do Paraná nos anos de 1950 a 1964, período que se refere aos governos de Bento Munhoz da Rocha Neto, Moyses Lupion e Ney Aminthas de Barros Braga. Para esse artigo pretendo apresentar um balanço de alguns estudos produzidos e que tratam da temática. Assim, dialogarei com as obras de Sônia Regina de Mendonça, José Graziano da Silva e Roseli Alves Santos, a partir das quais contextualizarei questões referentes as políticas públicas, sobre o ensino rural e a modernização da agricultura em âmbito nacional e estadual.

Palavras-chave: Politicas Públicas; Ensino Rural; Modernização da Agricultura.

Abstract: This work is based on the Final Paper I have been writing this academic year and it is focused on the public policies regarding agricultural modernization and rural education implemented by the State of Paraná between 1950 and 1964 - a period that encompasses the governorships of Bento Munhoz da Rocha Neto, Moyses Lupion and Ney Aminthas de Barros Braga. Thus I intend to present a review of some produced studies that deal with thematic. In this way, I deal with some works of Sônia Regina de Mendonça, José Graziano da Silva and Roseli Alves Santoswhich enabled me to contextualize some issues concerning public policies, rural education and agricultural modernization in both Brazil and the State of Paraná.

Keywords: Public Policies; Rural Education; Agricultural Modernization.

\footnotetext{
${ }^{1}$ Graduando do $4^{\circ}$ ano do curso de História da UNIOESTE - Universidade Estadual do Oeste do Paraná. Contato: ortiz.fabioadriano@ gmail.com
} 


\section{Introdução}

O processo de desenvolvimento da agricultura brasileira, a partir de 1950 passou por importantes transformações no que diz respeito às formas de produção e cultivo da terra. Tal processo ficou conhecido como a modernização da agricultura, sendo que este tema foi estudado por alguns pesquisadores visando vislumbrar as engrenagens e objetivos dos sujeitos operantes nesse período. Boa parte do que foi produzido referente a este tema foram pesquisas e obras de geógrafos, historiadores e sociólogos. Para este artigo foram feitas leituras que tratam desse processo em contexto nacional e estadual.

O cenário que se apresenta como escopo inicial do processo de modernização da agricultura, tem como base principal a expansão do sistema capitalista no pós Segunda Guerra. Como destaca Sônia Regina de Mendonça ${ }^{2}$, é neste período que se descobre a pobreza no mundo, e caberia aos países desenvolvidos a tarefa de conduzir os países pobres em seu processo de desenvolvimento.

Dentro desse contexto, há uma convergência de autores que discutem o tema. Tanto José Graziano da Silva, na obra "A modernização dolorosa", como Roseli Alves dos Santos em "O processo de modernização da agricultura no Sudoeste do Paraná”, apontam para a construção de um discurso que visava tecer uma 
oposição entre o "moderno" e o "arcaico", em que tal dinâmica estava pautada no processo de reprodução do capitalismo monopolista e que orientava para uma superação do atraso. Assim, aponta Graziano da Silva,"Com a esteriotipização do subdesenvolvimento mostrava uma economia onde o setor industrial era incipiente e o setor agrícola "atrasado", ganharam destaque os modelos dualistas que procuravam mostrar um antagonismo entre ambos"3 e continua afirmando que

[...] as propostas formuladas para a superação desse pretenso antagonismo derivavam da imitação do caminho percorrido pelos países desenvolvidos, como se o subdesenvolvimento fosse um estágio anterior desse processo, como se os países hoje ditos desenvolvidos tivessem sido um dia subdesenvolvidos. ${ }^{4}$

Dessa forma, tanto Graziano da Silva, Santos e Mendonça apontam para discursos similares no campo nacional, onde apesar da agricultura ter sido a principal fonte de geração de capital da economia nacional, esta passa a carregar o fardo de ser o motivo de atraso do Brasil em relação a outras nações no plano mundial. Estes discursos já estavam presentes no cenário econômico e político anterior a década de 1950, sendo que políticas voltadas para a industrialização nacional já

\footnotetext{
2 MENDONÇA, Sonia Regina. "ETA em marcha": os Estados Unidos e o "ensino" agrícola no Brasil (1945-60). In: Estado e educação rural no Brasil: alguns escritos. Rio de Janeiro: Vício de Leitura/Faperj, 2007. p. 79-110.

${ }^{3}$ SILVA, José Graziano da. A modernização dolorosa. Rio de Janeiro: Zahar Editores, 1981. p. 17.
} 
eram postas em prática no período do primeiro governo de Getúlio Vargas. Contudo, nesse período, apesar dos esforços voltados para a industrialização a agricultura ainda permaneceu como o "carro chefe" da economia nacional.

A partir da década de 1950, há a busca pelo desenvolvimento de uma política de racionalização da agricultura, com vistas a uma expansão da base da economia nacional. Essa política contribuiu tanto para o aumento da produção e da produtividade, quando para redução da mão de obra para as atividades rurais. Esse aumento da produção foi resultado de atribuição de técnicas, maquinários e insumos modernos. Porém, também gerou consequências como a expulsão de trabalhadores do campo e de pequenos proprietários.

Assim, o que se observa é a construção de um discurso visando uma ação prática de como deveria se organizar a agricultura brasileira. Dessa forma, para desenvolvimento do capitalismo monopolista no Brasil, mais precisamente no campo da agricultura, não haveria espaço para a policultura, ou seja, a produção deveria estar voltada para monoculturas, principalmente aquelas ligadas para atividade exportadora.

Nesse contexto, aponta-se para o papel exercido pelos Estados Unidos, na "condução" e difusão do que seriam as culturas agrícolas

${ }^{4}$ idem, p. 17. 
mais rentáveis. Como observa Miriam Hermi Zaar ${ }^{5}$, os Estados Unidos implementou um novo padrão alimentar, ou seja, através da via econômica e de interesses de seus produtores industriais, passaram a influenciar e consolidar um padrão do que seria produzido, como por exemplo, soja e trigo. No entanto, os países que não os produziam tiveram de importar tais produtos dos EUA, pondo este em posição confortável perante a economia mundial. Dessa forma, Segundo Zaar, no Oeste do Paraná:

\begin{abstract}
A introdução do cultivo da soja e do trigo, foi um exemplo marcante de como ocorreu a articulação entre Estado-ideologia-capital. Uma articulação que promoveu a modernização da agricultura no oeste paranaense, efetivando principalmente em função das necessidades do capital industrial, instalado recentemente no país: promover a venda de insumos e máquinas agrícolas e a compra de produtos agrícolas, através da troca. ${ }^{6}$
\end{abstract}

Observa-se a partir disso que a agricultura ainda exercia importante função na economia nacional. Porém, de modo diferente do período anterior, quando tinha para si o papel central da economia, bem como recebia maior incentivo das políticas estatais. A partir desse momento a agricultura passa a fornecer capitais para o processo de

\footnotetext{
5 ZAAR, Miriam Hermi. A produção do espaço agrário da colonização a modernização agrícola e formação do Lago de Itaipu. Cascavel: Edunioeste, 1999. p. 29

${ }^{6}$ idem, p.30
} 
industrialização que se instalava no Brasil, através da venda de produtos voltados a exportação, sendo inicialmente o café e posteriormente a soja e o trigo. Além disso, ela ainda gerava retorno de capitais na compra de produtos industrializados, já que a indústria inicial que se instalava estava voltada para a produção e atendimento das demandas agrícolas.

No contexto paranaense, o Estado esteve diretamente ligado ao projeto modernizante nacional. Porém, este não se deu de forma homogênea no que se refere à temporalidade e espaço agrário. Assim é valido ressaltar que a modernização ocorreu em períodos diferentes em determinadas regiões do estado. A tese de Roseli Alves dos Santos traz um contexto mais amplo desse processo no Paraná. Apesar de ter seu trabalho centrado mais na região Sudoeste do estado, a autora constata que na referida região, apesar da busca por práticas mais modernas, o próprio relevo fez com que determinadas práticas disseminadas no contexto nacional, não pudessem ser efetivadas em grandes extensões. Dessa forma, outras culturas como a do milho foram mais usuais, já que era utilizada como alimento na suinocultura. ${ }^{7}$ Porém, afirma ainda que a partir da implementação do maquinário agrícola, novas práticas foram incorporadas a região.

\footnotetext{
${ }^{7}$ SANTOS, Roseli Alves dos. O processo de modernização da agricultura no sudoeste do Paraná. Tese (doutorado em Geografia) - Programa de Pós-Graduação em Geografia, Universidade Estadual Paulista "Julio Mesquita Filho", Presidente Prudente, 2008. $\quad$ p. 246. Disponível em: http://www.athena.biblioteca.unesp.br/exlibris/bd/bpp/33004129042P3/2008/santos_r a_dr_prud.pdf, acesso em 29/09/2013.
} 
Miriam Hermi Zaar desenvolve análise cujo foco é a região Oeste do estado. Em seu estudo, demonstra que o processo de modernização da agricultura teve um início mais tardio nesta região. A autora destaca que isso foi decorrente do processo de colonização da região que teve início na década de 1940, destacando que os municípios aos quais concentra seu estudo tiveram suas fundações a partir da década de 1950, o que inicialmente levou tal região a extração e comércio de madeira, efetivando o processo de modernização da agricultura posterior a década de $1970 .^{8}$

No que é referente ao Norte do Paraná, a região possuía um protagonismo tanto na agricultura como na economia do estado. Tal protagonismo estava pautado na cultura cafeeira, que até então era um dos principais produtos voltados para a exportação em âmbito nacional, o que conferia a região um grande peso político e econômico. Porém, como afirma Margarida Cassia Campos

[...] a geada de 1953 forçou os produtores a plantar cereais como cultura, intercalando entre as "ruas" dos cafezais. Porém, esta ação não teve êxito devido às dificuldades de transporte e comercialização. Em 1955, procurando arranjar uma solução para outra grande geada ocorrida no mesmo ano, o Instituto Agronômico de Campinas sugeriu o cultivo da soja entre os cafezais para amenizar a situação. Nesse contexto, tais ações surgiram para incentivar outra cultura que pudesse ser colocada a bom preço no mercado internacional e que causasse o menor

\footnotetext{
${ }^{8} \mathrm{ZAAR}$, op cit.
} 
malefício aos cafezais em formação. A resposta do Paraná foi imediata: de 43 hectares plantados de soja em 1954, passou para 1.922 em 1955 e 5.253 em $1956{ }^{9}$

Observa-se nesse contexto, o intervencionismo direto do Estado na busca pela substituição da cultura até então predominante na região norte do Paraná, o café. Dessa forma é visível a preferência pelos setores dirigentes voltados a produção rural de que se buscasse produzir soja, sendo esta mais rentável e de menos riscos de produção, bem como alavancar as exportações gerando capital suficiente para subsidiar o processo de industrialização em curso.

Não somente a questão da modernização da agricultura buscou aumentar a capacidade produtiva, como também buscava transformar os braços utilizados até então na produção agrícola, em braços para as indústrias em formação. Desse modo, a introdução de novas técnicas e maquinários agrícolas contribui para um processo de êxodo dos trabalhadores rurais, para que fosse possível gerar uma mão de obra urbana suficiente a ponto de haver sobras e como consequência disso, o barateamento dessa mão de obra para as indústrias.

Dessa forma, com o processo de "esvaziamento" do campo, a atividade agrícola não somente no Paraná, mas em âmbito nacional,

${ }^{9}$ CAMPOS, Margarida Cassia. Modernização da agricultura, expansão da soja no Brasil e as transformações socioespaciais no Paraná. Revista Geografar, v.6, n.1, p. 161-191, jun./2011.

p.

179.

Disponivel

em: http://ojs.c3sl.ufpr.br/ojs2/index.php/geografar/article/view/21808/14203, acesso em 29/09/2013. 
passa a depender de outros instrumentos para a produção que até então eram supridos por uma massa de trabalhadores rurais. Assim, o processo iniciado com a implementação de novas técnicas e insumos agrícolas que visavam uma maior produção bem como a melhor utilização dos espaços voltados para esta, atinge um novo patamar.

Como destaca Graziano da Silva

[...] a modernização aumenta as exigências e diminui o período de ocupação da mão-de-obra nãoqualificada numa dada propriedade agrícola. A solução mais econômica para o proprietário que moderniza passa a ser a substituição do trabalhador permanente pelo volante, como o conseqüente aumento da sazonalidade do emprego dos trabalhadores rurais. ${ }^{10}$

Assim, além do decorrente processo de êxodo rural existente em âmbito nacional, a indústria instalada no Brasil passa a ver aumentada a demanda por maquinário agrícola. Em outras palavras, o processo de deslocamento de trabalhadores para os centros urbanos, aliado a utilização de novas técnicas de produção e a adoção de insumos modernos como agrotóxicos, herbicidas e etc., faz com que a agricultura passe a necessitar de maquinários para facilitar o trabalho bem como dar mais celeridade a atividade produtiva e o consequente aumento da produção.

\footnotetext{
${ }^{10}$ GRAZIANO DA SILVA, op cit, p. 30
} 
Nesse contexto, observa-se o estabelecimento no Brasil de políticas voltadas para o crédito rural e a criação de instituições estatais de financiamento da atividade agrícola. Assim, Pedro Cassiano Farias de Oliveira afirma que

$\mathrm{O}$ discursos veiculado pela $\mathrm{ABCAR}^{11}$ era da inevitabilidade da industrialização para o desenvolvimento do país. Paralelamente, a agricultura deveria modernizar-se pois não poderia contar com o contingente de mão-de-obra, pois a industrialização forçava o êxodo rural. Para a aquisição dos insumos e maquinaria que aumentaria a produção fazia-se necessário o crédito rural, aliado a uma atividade de Extensão Rural que ensinaria o agricultor a implantar as novas técnicas agrícolas. ${ }^{12}$

Dessa forma, o que se buscava com a criação dessas instituições era financiar a atividade agrícola, bem como incentivar a aquisição de maquinários ditos modernos e facilitadores de tal atividade, como por exemplo, a utilização de tratores. Porém, o acesso a estes financiamentos era restrito aos grandes proprietários de terra, cuja propriedade da terra era uma forma de garantia do pagamento do financiamento. Nesse contexto, o pequeno produtor acabava por se ver em dificuldade para manter-se no meio rural o que por muitas vezes

\footnotetext{
${ }^{11}$ ABCAR - Associação Brasileira de Crédito e Assistência Rural

12 OLIVEIRA, Pedro Cassiano de. Estado, extensionismo rural e grupos dominantes agrários no Brasil (1948-1974). Disponível em:http://www.historia.uff.br/estadoepoder/files/pedroCassiano_estadoExtensionismo Rural.pdf, acesso em 30/04/2014. p.6
} 
fazia com que vendesse sua terra e buscasse melhor sorte nos centros urbanos.

E valido salientar, como também enfatiza Pedro Cassiano, a inserção do capital estrangeiro, principalmente o estadunidense, na condução e efetivação dessa política de crédito bem como de extensionismo agrícola. Nesse contexto, o autor traz a ação direta de um nos agentes estadunidenses nesse processo, que foi Nelson Rockfeller, o qual firmou convênios com governadores de estados e exerceu influência direta no processo de efetivação da extensão agrícola no país. $^{13}$

O próprio Estado do Paraná, através de uma de suas entidades criadas para a agricultura, a EMATER, veicula em seu histórico oficial a importância e o papel dos extensionistas e técnicos, que buscavam orientar esforços para o processo de modernização da agricultura. Nestes termos, consta no site oficial da referida entidade que

A partir de meados da década de 50, no século passado, o meio rural paranaense, até então pouco conhecido, começou a ser desvendado. Os agricultores e suas famílias tiveram os primeiros contactos com extensionistas rurais. Os técnicos faziam muitas perguntas, percorriam as lavouras, olhavam as criações, analisavam as condições de vida das famílias e, principalmente, tomavam nota de tudo, também levavam informações e novidades sobre as formas de produção agrícola, saneamento, alimentação e outros temas de interesse das famílias.

${ }^{13}$ OLIVEIRA, $o p c i t$ 
As anotações resultam nos documentos denominados "Realidade Municipal" com foco no rural, com informações fundamentais para $\mathrm{o}$ conhecimento das atividades agrícolas e das condições de vida das famílias rurais além de indicarem caminhos para a melhoria da qualidade de vida e de estratégias de "modernização" do setor rural. Esses documentos foram exaustivamente utilizados na formulação de planos e projetos, tanto pelos extensionistas quanto por prefeituras e outras organizações privadas. ${ }^{14}$

É possível observar, diante de tal histórico, que, até a década de 1950, segundo o discurso oficial, havia pouco conhecimento dos modos como a agricultura paranaense se desenvolvia. Então, surge uma entidade capaz de desenvolver a agricultura no Paraná e que acabaria por resolver os problemas existentes no setor agrícola, levando à modernização. Outro ponto é a relevância dada ao tema da modernização, que somente a partir da criação da instituição, de acordo com o histórico oficial, é que foi possível a implementação do processo modernizante no meio rural paranaense.

Outras entidades foram criadas a partir de acordos entre o governo brasileiro e o governo estadunidense, dentre as quais destaca-se o ETA - Escritório Técnico de Agricultura Brasileiro-Americano. De acordo com os estudos de Sonia Regina de Mendonça

\footnotetext{
${ }^{14}$ Sitio da EMATER - Instituto Paranaense de Assistência Técnica e Extensão Rural. Histórico da Extensão Rural Oficial. Disponível em: http://www.emater.pr.gov.br/modules/conteudo.php?conteudo=43. Acesso em 19/10/2013.
} 
[...] os quadros do ETA definiam como seu objetivo "contribuir para o avanço econômico dos países subdesenvolvidos”, mediante projetos específicos junto a áreas como a Extensão e o Crédito Rural subsidiado. Nesse sentido, ele desenvolveu inúmeros projetos - contratados tanto por entidades públicas, quanto privadas - funcionando mediante seu assessoramento e/ ou financiamento e não mais [...] por intermédio de medidas e ações unificadas que configuravam um programa geral de cooperação. Esses projetos abrangiam iniciativas junto a todas as unidades da federação brasileira e incidiam sobre os mais distintos âmbitos do universo agrário, envolvendo desde o fomento à produção agropecuária e a conservação de recursos naturais até - e, sobretudo - auxilio técnico - "educativo" a comunidades locais rurais. ${ }^{15}$

Por meio dessas informações podemos perceber que houve uma grande participação dos EUA nas atividades produtivas em vários países da América Latina, de tal modo que técnicos estadunidenses estiveram presentes no desenvolvimento de projetos e no estabelecimento de práticas no setor agrícola brasileiro.

A partir do que foi apresentado até aqui é possível verificar que as pesquisas que foram desenvolvidas sobre o tema da modernização da agricultura concordam que a década de 1960 foi um momento definidor dos rumos desse processo. O que explica esse direcionamento é o fato de que, a partir desse momento, passam a ser implementadas no meio

\footnotetext{
${ }^{15}$ MENDONÇA, op cit p. 79 (Grifos da Autora)
} 
rural as novas técnicas, novos insumos e maquinários. Por sua vez, isso não é uma novidade, pois em períodos anteriores da história do Brasil também existiram esforços e políticas voltadas a modernização da agricultura. Contudo neste momento em específico a vinculação entre Estado, agências estatais, sociedades patronais, empresas multinacionais e o governo estadunidense passam a atuar conjuntamente objetivando realizar a referida modernização. Outro ponto a se salientar dentro dessa convergência é o fato de que a industrialização no Brasil, através do discurso oficial, passa a ter um caráter de indispensabilidade, que fica mais evidente a partir do governo de Juscelino Kubitschek na década de 1950, com o discurso e projeto altamente ideologizante dos "cinquenta anos em cinco".

\section{A educação e a modernização da agricultura}

O primeiro fator importante referente á educação voltada para práticas modernas na agricultura, é a compreensão dos diferentes momentos em que ela tornou-se usual para este objetivo. Em dois períodos específicos a educação teve peso direto nesse processo. $\mathrm{O}$ primeiro período é referente ao pós abolição do trabalho escravo e o segundo efetivou-se a partir de 1930 mais incisivamente no período após a Segunda Guerra Mundial, onde diferentes sujeitos e interesses 
permearam as disputas em torno do projeto modernizador da agricultura. ${ }^{16}$

Com referência ao primeiro período, após a abolição do trabalho escravo no Brasil, a preocupação inicial dos grandes proprietários de terra, era buscar alternativas para manter os trabalhadores no campo. Nesse período se implantaram as primeiras políticas voltadas para a qualificação do trabalhador rural, pautadas na superação das formas de produção apresentadas e consideradas atrasadas. Tais políticas foram implementadas inicialmente pelo MAIC - Ministério da Agricultura, Indústria e Comércio, criado em 1910, o qual buscou congregar e efetivar os interesses da burguesia agrária brasileira. ${ }^{17}$

Sonia Regina de Mendonça destaca que nesse período foram criadas diversas unidades de ensino agrícola, como os Aprendizados e os Patronatos Agrícolas. ${ }^{18}$ Organizados pelo MAIC, essas instituições buscavam "ensinar" os alunos de séries iniciais, noções de trato com a terra, bem como prepará-los para o trabalho na agricultura moderna no objetivo da superação do atraso.

Já no que se refere ao período que se inicia a partir da década de 1930, este pode ser dividido em outros dois períodos: o primeiro de 1930 a 1945; e o segundo posterior a Segunda Guerra Mundial. Porém,

\footnotetext{
${ }^{16}$ MENDONÇA, Sonia Regina. Estado e educação rural no Brasil: alguns escritos. Rio de Janeiro: Vício de Leitura/Faperj, 2007.

${ }^{17}$ idem

${ }^{18}$ Ibidem
} 
ambos são em parte semelhantes no tocante a atuação de organismos e organizações presentes nesse processo.

No que compreende o período de 1930 a 1945, é criado neste cenário em 1931 o Ministério da Educação e Saúde - MES, que passa a coordenar os projetos voltados a educação. A partir disso surgem atritos entre o MAIC, que até então era o órgão que desenvolvia as políticas referentes à educação rural, e o MES, que interfere diretamente nos projetos voltados para a educação rural, com destaque para a busca por uma educação mais voltada para a alfabetização, ao contrário da educação voltada para a qualificação e preparação da mão-de-obra.

Nesse contexto, Sonia Regina de Mendonça chama atenção para os atritos existentes entre as frações da classe dominante no Brasil, sendo que tais estão ligados a burguesia urbana, em torno do MES e a burguesia agrária arregimentada em torno do MAIC. Para tanto, observa a disputa entre o modelo de educação defendido por esses dois grupos e os ministérios do Estado que ambas ocupavam. De um lado o Ministério da Educação e Saúde possuía um orçamento mais volumoso e visava desenvolver um ensino o qual buscasse contemplar sua parcela dominante, com uma abordagem mais pautada no conhecimento político, com objetivo de formar novos dirigentes que defenderiam seus interesses, diferente do modelo veiculado pelo MAIC, voltado mais especificamente a formação de mão de obra especializada. Assim Ministério da Agricultura, dominado pela burguesia agrária, via seus recursos diminutos, e o consequente estrangulamento de seu projeto. 
Dentro desse contexto a autora destaca que o fato do envio de escassos recursos por parte do Ministério da Educação, para a manutenção das escolas agrícolas, dificultou a sua manutenção. ${ }^{19}$

A disputa Ministério da Agricultura versus Ministério da Educação ganharia novos contornos a partir do envolvimento dos Estados Unidos na Segunda Grande Guerra, do qual resultou a assinatura do primeiro dos tratados firmados entre aquele país e a Pasta da Produção, dando origem à Comissão Brasileiro-Americana para a Produção de Gêneros Alimentícios, em 1942. Esta, através de recursos norte-americanos, atuaria junto às instituições de ensino agrícola incrementando a formação de trabalhadores rurais destinados a maximizarem a produção dos gêneros de primeira necessidade necessários ao "esforço de guerra". ${ }^{20}$

A partir da assinatura desse tratado, como enfatiza Mendonça, é que a influência e ação estadunidense, no tocante a educação rural no país se faria mais efetivamente. Os EUA, através de acordos firmados com o governo brasileiro, passam a financiar a pasta de agricultura com o objetivo de criar mais estabelecimentos de ensino agrícola no país. Tais estabelecimentos foram as Escolas de Iniciação Agrícola, Escolas Agrícolas, Escolas Agrotécnicas, Cursos de Aperfeiçoamento, Especialização e Extensão e Centros de Treinamento $^{21}$, os quais tinham

${ }^{19}$ MENDONÇA, op cit, p. 64-65

${ }^{20}$ MENDONÇA, op cit, p. 66

${ }^{21}$ MENDONÇA, op cit, p. 72 
como função prover educação agrícola desde as séries iniciais até cursos mais avançados sobre a agricultura e suas técnicas modernas.

Ainda dentro desse contexto, houve o incentivo pelo Ministério da Agricultura para a formação dos Clubes Agrícolas, que segundo Mendonça

[...] acabou por introduzir uma nova duplicidade junto ao já dicotômico sistema de ensino brasileiro, uma vez que, embora definidos como entidades "extra-escolares", incumbidas de divulgar conhecimento sobre a vida no campo, funcionavam em anexo às escolas primárias da zona rural e, em certos casos da própria cidade ${ }^{22}$.

A partir disso, observa-se que o ensino agrícola buscou, através da ação do Ministério da Agricultura, ampliar seus tentáculos para além das instituições de ensino oficiais, para que assim, o ideal modernizante se fizesse presente nas mais distintas relações sociais dos sujeitos envolvidos.

Como enfatizado, o interesse estadunidense com referência a educação rural já se fazia perceber durante o período da Segunda Guerra Mundial. Com o consequente fim do conflito a ação dos EUA tem um crescente aumento com a firmação de novos acordos entre governo brasileiro e estadunidense, principalmente ligados a pasta de agricultura. Entre esses acordos, o mais expressivo e que possuía ação

${ }^{22}$ MENDONÇA, op cit, p. 74 
direta sobre a agricultura foi o já citado ETA - Escritório Técnico de Agricultura Brasileiro-Americano, que objetivou desenvolver políticas visando a difusão da extensão agrícola, técnicas modernas de produção, etc.

Nesse contexto, a extensão agrícola também desempenhou papel importante na difusão dos ideais modernizantes por meio da educação. Através de técnicos, o produtor seria orientado sobre como fazer o uso de novas máquinas agrícolas, pois segundo essa lógica de nada adiantaria a utilização de máquinas modernas se o produtor não tivesse o conhecimento necessário para o seu manejo ${ }^{23}$. Assim os extensionistas, além de "passar" esse conhecimento ao produtor, embutiriam a necessidade de compra dessas máquinas para o aumento da produção.

É válido salientar o claro interesse estadunidense nesse processo, via ação educacional. Tal fato se revela no contexto mundial desse período, onde o mundo estava dividido em dois grandes blocos econômicos, o socialista e o capitalista. Assim, o interesse dos EUA, além do aumento de sua área de ação econômica, visava a difusão do pensamento capitalista em oposição ao socialismo.

Já no que é referente ao Estado do Paraná, as políticas educacionais voltadas para a área rural não se diferiam das práticas nacionais. Etelvina Maria de Castro Trindade e Maria Luiza Andreazza destacam que 
"[...] com Munhoz da Rocha, apareceram as Escolas de Pesca e Trabalhadores Rurais e os serviços de Publicidade Agrícola, sempre na intenção de fornecer orientação técnica ao trabalhador rural e dar um novo impulso aqueles que até hoje se guiavam por métodos empíricos e rotineiros. Dessa forma, a transmissão de práticas de higienização e disciplinarização das novas populações completava a obra de ocupação e povoamento. ${ }^{24}$

Observa-se a preocupação em relação aos métodos que até então eram utilizados e a necessidade de superá-los - discurso que se assemelha com o citado histórico oficial da EMATER - como também a busca por práticas de higienização e a disciplinarização da população rural. Ou seja, a preocupação com a disciplina tem ligação direta com o contexto nacional e mundial.

\section{Conclusão}

As políticas públicas voltadas para a modernização da agricultura, em âmbito nacional e estadual, estiveram ligadas aos interesses econômicos nacionais e internacionais, visando de maneira

\footnotetext{
${ }^{23}$ OLIVEIRA, op cit

${ }^{24}$ TRINDADE, Etelvina Maria de Castro; ANDREAZZA, Maria Luiza. Planejamento Educacional e Movimentos Intelectuais. In: Cultura e Educação no Paraná. Curitiba SEED, 2001. p. 105
} 
particular a ampliação do modo de produção capitalista a partir do fomento de um modelo específico de atividade agrícola.

Contudo, como o evidenciado pelos estudos analisados, a modernização da agricultura não pode ter seu processo relegado somente a partir da década de 1950, com a introdução de maquinários e novas técnicas na atividade produtivas. Como verificado, o processo de modernização da agricultura já vinha sendo implantado em períodos anteriores, através políticas educacionais que primeiramente buscavam manter o trabalhador rural no espaço agrário dando-lhes "instrução" acerca do processo produtivo. Dessa forma, nos anos 1930 até 1950, como consagrado por parte da historiografia como a efetiva modernização da agricultura, por políticas que objetivaram preparar o trabalhador/produtor rural para a utilização dessas novas técnicas e maquinários, bem como estas buscaram manter o controle destes trabalhadores sobre a égide do Estado.

\section{Referências}

CAMPOS, Margarida Cassia. Modernização da agricultura, expansão da soja no Brasil e as transformações socioespaciais no Paraná. Revista Geografar, v.6, n.1, p. 161-191, jun./2011. p. 179. Disponivel em:

http://ojs.c3sl.ufpr.br/ojs2/index.php/geografar/article/view/21808/1420 3, acesso em 29/09/2013. 
MENDONÇA, Sonia Regina. Estado e políticas públicas no Brasil: uma questão conceitual. In: Estado e educação rural no Brasil: alguns escritos. Rio de Janeiro: Vício de Leitura/Faperj, 2007.

OLIVEIRA, Pedro Cassiano de. Estado, extensionismo rural e grupos dominantes agrários no Brasil (1948-1974). Disponível em: http://www.historia.uff.br/estadoepoder/files/pedroCassiano_estadoExte nsionismoRural.pdf, acesso em 30/04/2014.

SANTOS, Roseli Alves dos. O processo de modernização da agricultura no sudoeste do Paraná. Tese (doutorado em Geografia) Programa de Pós-Graduação em Geografia, Universidade Estadual Paulista "Julio Mesquita Filho", Presidente Prudente, 2008. p. 246. Disponível em: http://www.athena.biblioteca.unesp.br/exlibris/bd/bpp/ 33004129042P3/2008/santos_ra_dr_prud.pdf, acesso em 29/09/2013.

SILVA, José Graziano da. A modernização dolorosa.Rio de Janeiro: Zahar Editores, 1981.

Sítio da EMATER - Instituto Paranaense de Assistência Técnica e Extensão Rural. Histórico da Extensão Rural Oficial. Disponível em: $<$ http://www.emater.pr.gov.br/modules/conteudo/conteudo.php?conteud $\mathrm{o}=43>$. Acesso em 23/10/2013. 
TRINDADE, Etelvina Maria de Castro; ANDREAZZA, Maria Luiza. Planejamento Educacional e Movimentos Intelectuais. In: Cultura e Educação no Paraná. Curitiba - SEED, 2001.

ZAAR, Miriam Hermi. A produção do espaço agrário da colonização a modernização agrícola e formação do Lago de Itaipu. Cascavel: Edunioeste, 1999. 